\title{
Stage 1 Registered Report: \\ The influence of journal submission guidelines on authors' reporting of statistics and use of open research practices: five years later
}

\author{
Ingrid Boedker*, David Giofrè*, Geoff Cumming ${ }^{\S}$ and Patrizio Tressoldi $^{1 \circ}$ \\ *Department of Education, DISFOR, University of Genoa, Italy

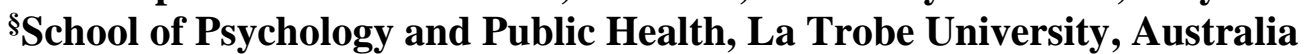 \\ ${ }^{\circ}$ Studium Patavinum, University of Padua, Italy
}

[version 10/19/2021]

\begin{abstract}
Changes in statistical practices and reporting have been documented by Giofrè et al. (2017), who investigated ten statistical and open practices in two high ranking journals (Psychological Science [PS] and Journal of Experimental Psychology-General [JEPG]): These included null hypothesis significance testing; confidence or credible intervals; meta-analysis of the results of multiple experiments; confidence intervals interpretation; effect size interpretation; sample size determination; sample size stopping rule; data availability; materials availability; and preregistered design and analysis plan.
\end{abstract}

The investigation was based on an analysis of all papers published in these journals between 2013 and 2015.

The aim of the present study is to follow up changes in both PS and JEPG in subsequent years, from 2016 to 2020 , adding code availability as further open practice.

Keywords: statistical practices; open science practices; authors submission guidelines.

\footnotetext{
${ }^{1}$ Corresponding author: patrizio.tressoldi@unipd.it
} 


\section{Introduction}

Trust in psychological findings has eroded over the last decade, as many of the published reports in this area have been found not to be fully replicable (Camerer et al., 2018; Open Science Collaboration, 2015). This observation has led scientists, funders, research users, and policy makers to investigate the reasons behind the absence of replicability (e.g., Goodman et al., 2016). Several factors have been considered, including the presence of questionable research practices, statistical problems (including low statistical power), and barriers to data sharing, including a lack of encouragement and training from journals and institutions to publicly share data (Agnoli et al., 2017; Houtkoop et al., 2018; Szucs \& Ioannidis, 2017; Tressoldi \& Giofrè, 2015). To overcome these problems, several journals have introduced new statistical guidelines, which encompass new statistical standards and other research practices, including providing raw data and other materials online.

One influential approach, advocated by Cumming $(2013,2014)$, has been use of the socalled "New Statistics", a set of best practices for making inferences from data (Calin-Jageman \& Cumming, 2019). Included are the need: i) to address uncertainty in all statistical conclusions, seeking ways to quantify, visualize, and interpret the potential for error (e.g., by including confidence intervals or Bayesian credible intervals); ii) to pursue replication, and use quantitative methods to synthesize across different data sets (e.g., performing meta-analyses or using informed priors); and iii) to use Open Science practices to enhance the trustworthiness of research results. In order to increase the uptake of these practices, some journals have explicitly recommended their use in the journal requirements / instructions for authors, which has had an impact in changing researchers' behaviour and increasing openness, data sharing, and data availability (Giofrè et al., 2017; Kidwell, Lazarević, Baranski, Hardwicke, Piechowski, Falkenberg, et al., 2016).

The changes in statistical practices and reporting have been documented by Giofrè et al. (2017), who investigated the statistical practices and open practices in two high ranking journals (Psychological Science [PS] and Journal of Experimental Psychology, General [JEPG]). The 
investigation was based on an analysis of all papers published in these journals between 2013 and 2015. Results showed that the introduction of new statistical guidelines, in particular for PS, led to an improvement in most statistical practices, for example, reporting confidence or credible intervals, and reporting more information about the sample (e.g., sample size determination and data exclusion practices). Concerning Open Practices, the authors found that the inclusion of new guidelines were beneficial, for example, in increasing the number of papers providing raw data and additional materials. However, the authors also found some limits related to the introduction of these new practices and guidelines.

Since 2015, more than 2,000 journals have adopted at least some of the Transparency and Openness Promotion Guidelines (Nosek et al., 2015) in their journals, and a general improvement in statistical practices has also been documented in recent years by Blanca and colleagues (2018). However, the introduction of new practices might, despite these being beneficial, have led to only superficial changes. In 2015-2017, PS and JEPG were still over-reliant on an NHST approach (i.e., an approach overly focused on the $p$-value and not on the interpretation of the effect size or using a different approach, such as Bayesian). And now, although researchers may be reporting more information, they may still be interpreting and basing their conclusions using a traditional NHST approach, which has been criticized on several occasions (Tressoldi et al., 2013).

Giofrè and co-authors (2017) also found that, although the use of preregistration had been strongly recommended by PS in the new guidelines, it was scarcely used in both PS and JEPG. By 2018, proponents of preregistration were still calling it an emerging practice (Nosek, Ebersole, DeHaven, Mellor, 2018). Because they were relatively new when the previous research was conducted, it is worth investigating whether preregistrations have become more prevalent in recent years. Finally, since the previous research was limited to only three years, the question of the general long-term effects of the changes remains to be fully addressed.

As far as changes in the guidelines in recent years are concerned, it is possible to compare vis-à-vis the results of the current report with the results presented by Giofrè et al. (2017). While the 
2020 edition (7th ed.) of the Publication Manual has recently been released (American

Psychological Association, 2020), it will take time to see changes implemented on a journalspecific level. The past and present research concerns the instructions to authors given by the editors of journals, not the APA. This difference is crucial, as previous research has shown that simply referring authors to an external source (such as APA) may not be as effective as publishing journal-specific guidelines (Giofrè et al., 2017).

PS recently updated its guidelines on August $18^{\text {th }}, 2021$, which can be found here: https://www.psychologicalscience.org/publications/psychological_science/ps-submissions. These guidelines remain very similar to the ones published 2015, with some parts reworded. For example, in the previous version, PS asked authors to provide a rationale for the sample size; in 2021 they specified where in the manuscript this should go. A blurb was added about replicability being not the only consideration but an important one; authors are also now encouraged to use graphical presentations to show how data are distributed and to include information about sample sizes in the manuscript's abstract.

Similarly, JEPG's updated guidelines from July $1^{\text {st, }} 2021$, which can be found here: https://www.apa.org/pubs/journals/xge/. Recent changes have included requiring authors to state whether data are publicly available and where they can be accessed; whether or not work has been preregistered; and an endorsement of the Transparency and Openness Promotion (TOP) Guidelines (Open Science Foundation, 2020). Time will tell how these specific guidelines will affect transparency in the long run, but for the purposes of the present study, in the period from 2016 to 2020, these journal-specific guidelines, or in the case of JEPG, a lack thereof, had not changed markedly.

The aim of the present study is to follow up changes in both PS and JEPG in subsequent years, from 2016 to 2020 . We will continue to investigate these changes' long-term effects on authors' statistical practices as well as to add one further research practice to investigate. In addition to the original criteria, we will investigate statistical code, or script, availability (typically R code). 
Subsequent to the publication of the original report (Giofrè et al., 2017), many psychological researchers have started to learn dynamic writings such as Rmarkdown, which is useful for fully reproducing the results and has been endorsed recently by Goldacre and co-authors (Goldacre et al., 2019) and covered in the TOP Guidelines (Open Science Foundation, 2020). In light of the multilevel approach taken in the TOP Guidelines (Open Science Foundation, 2020), the current research will also employ an additional level of coding to specify how researchers have addressed questions, e.g., in the case of data availability, listing where the data are available.

We hypothesize a continuation of the findings of Giofrè et al. (2017), namely a greater uptake in the studied research practices in PS, which changed its journal submission guidelines in 2014, as compared to JEPG, which referred to third-party guidelines. Apart from a continuing increase in the adoption of the open practices, as observed in Giofre et al (2017), we expect a much smaller increase in the interpretation of results taking in account the confidence intervals and the effect sizes of the main outcomes in both journals and an overreliance on dichotomous interpretations, e.g. there is/there is not a difference, a correlation or a superiority of model X with respect to model Y, etc. instead of dimensional interpretations, e.g. there is a strong/small difference, correlation, etc.

\section{Materials and method}

The database for the present study will be posted on an online open access repository. For comparison, the data from Giofrè et al. (2017) are available here: https://figshare.com/s/dd5756ad2826360e2ebf

\section{$\underline{\text { Inclusion and exclusion criteria. }}$}

All papers published in PS and JEPG between January 1st, 2016, to December 31st, 2020, will be considered. Only primary empirical papers reporting data from one or more empirical studies and their online supplemental materials, when available, will be considered. Papers only 
reporting meta-analysis, narrative reviews, simulation, comments, and theoretical studies will be excluded. [Please note that we will exclude papers with a meta-analysis of multiple papers, while meta-analysis of multiple findings achieved in one paper will not be excluded. These inclusion and exclusion criteria are identical to those used by Giofrè et al. (2017).]

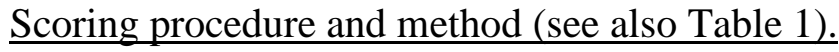

The scoring procedure and method is identical to the procedure adopted by Giofrè et al. (2017) except for the inclusion of a new practice (the $11^{\text {th }}$ ). The list of practices reported below has been adapted from Cumming (2013), the Open Science Framework badges scheme (Kidwell et al., 2016; Blohowiak, Cohoon, de-Wit, Eich, Farach, Hasselman, et al., 2020), and the TOP Guidelines (Open Science Foundation, 2020).

Scoring procedure and method (see also Table 1). Published journal articles, and the online supplemental material when available, were considered. A single occurrence of a practice anywhere in the published paper was sufficient for a coding of ' $\mathrm{Y}$ ' (yes), indicating that this practice was adopted. Papers were examined for the following ten practices:

1. NHST. A $p$ value was reported, whether exact (PE; e.g., $p=.036$ ) or relative (PA; e.g., $p<.05)$. We reported the overall proportion of papers adopting this practice and distinguished between papers that reported mainly the exact or relative value.

2. CI. A confidence interval was reported. CI counted all cases with any confidence interval. We reported the overall proportion of papers with at least one confidence interval for either standardized or unstandardized measures.

3. MA. Meta-analysis of multiple related results included in the paper was reported. We only included papers with more than one result related to the same empirical question.

4. CI_interp. A confidence interval was referred to in the discussion or interpretation of results, upon which data interpretation was explicitly based. For example, this would include a 
paper explicitly mentioning the width or the precision of the CI, a comparison between two or more CIs, or an overlapping between two intervals.

5. ES_interp. An effect size, either standardized or unstandardized, was referred to in the discussion or interpretation of results. We considered 'effect size' in the broad sense (17), including means, differences between means, percentages, and correlations, as well as Cohen's $d$, $R^{2}$, and $\eta^{2}$. Papers were considered which included not only a dichotomous difference vs. no difference approach, but also those referring to the magnitude of the effect (e.g., small, large, strong etc.) or to the amount of explained variance. Effect size could be expressed in original units, or in some standardized or units-free form.

6. Sample_size. The authors described how sample size(s) were determined. For example, a power analysis - based on previous research, or on an estimated effect size - had been conducted. We used a very lenient approach, including all papers vaguely mentioning how the sample size was determined (e.g., the sample size was determined based on previous research, etc.).

7. Data_excl. The authors reported the criteria for data inclusion or exclusion—-for example, the criteria for the exclusion of outliers.

8. Data. The paper carried the Open Data badge (see below), or stated where the data were available or how they could be obtained. We used a very lenient approach, including all the papers mentioning that data were available (e.g., data are available upon request).

9. Materials. The paper carried the Open Materials badge, or stated where details of the experimental materials and procedure could be obtained. We used a very lenient approach, including all the papers mentioning that materials were available (e.g., materials are available upon request).

10. Preregistered. The paper carried the Preregistered badge, or stated where a preregistered plan had been lodged in advance of data collection. Papers in this category typically included information about the number of the preregistration or where the preregistration is available. 
11. Code. The paper carries computer code or syntax (e.g., R code), provided either in the supplementary materials, or in the preregistration, needed to reproduce the analyses. We used a very lenient approach, including all papers carrying the code in the paper or in the preregistration (e.g., we did not check if the code is sufficient to successfully replicating all the analyses presented in the paper).

The three badges (i.e., Data, Materials and Preregistration) are described in detail by the Center for Open Science (tiny.cc/badges; accessed September 2021). For PS, these badges were certified by an "earned badge" from the Open Science Framework (https://osf.io/tvyxz/wiki/home; accessed September 2021). Where badges have been awarded that might guide our coding, we will still check whether or not authors clearly indicated how to obtain the data, materials, and code.

The Open code badge is described here: https://www.bihealth.org/en/translation/innovationenabler/quest-center/mission-approaches/open-science/open-code-badge

For JEPG, badges are not available, but we will check whether or not authors clearly indicated how to obtain the data, materials and code.

\section{Data analysis}

\section{$\underline{\text { Scoring method and reliability }}$}

The first level of scoring method and reliability will follow exactly the same rules as the original Giofrè et al. (2017), while an additional level will be employed, where applicable, to specify the information given. These procedures are reported below.

Papers will be examined for the presence of each of the eleven practices. For each of them, the score could be "Y" (yes) if present.

Papers will be divided by the authors and independently scored. The authors are experienced researchers with good knowledge of the statistics examined. Secondly, a random sample comprising ten percent of the papers will be scored independently by both raters to test inter-rater reliability. Discrepancies will be solved by discussion. 
Only descriptive statistics will be reported given that they refer to the whole populations of studies. For each of the eleven practices analyzed, the number of papers including a practice will be expressed as a proportion of the total number of papers. Only for the meta-analysis (MA) will we exclude from the total papers those for which the meta-analysis criterion will not be applicable (NA), namely papers with a single study. The checklist for study examination is presented in Table

1.

Table 1. Checklist for study examination, related to the core experiment(s) and not to pilot ones.

\begin{tabular}{|c|c|c|c|c|}
\hline \multicolumn{5}{|l|}{ Paper ID: } \\
\hline Statistics & Value & Labels & Pag & Criteria for 'Yes' response \\
\hline $\begin{array}{l}\text { 1-Null hypothesis } \\
\text { significance } \\
\text { testing }\end{array}$ & $\begin{array}{l}\mathrm{PE}(p \\
\text { exact }) \\
\mathrm{PA}(p \\
\text { relative })\end{array}$ & NHST & & $\begin{array}{l}\text { At least one } p \text { value is reported; format: exact: e.g. } p= \\
0.35 \text {; relative: e.g.. } p<.05 \text {. } \\
\text { Add other different types of statistics if available: e.g. } \\
\text { Bayes; SEM, etc. }\end{array}$ \\
\hline $\begin{array}{l}\text { 2-Confidence } \\
\text { intervals }\end{array}$ & $\mathrm{Y}$ & $\mathrm{CI}$ & & $\begin{array}{l}\text { At least one is reported; specify where: text, tables, } \\
\text { figures; }\end{array}$ \\
\hline \multicolumn{5}{|l|}{$\begin{array}{l}\text { Statistical } \\
\text { approach }\end{array}$} \\
\hline $\begin{array}{l}\text { 3-Meta-analysis of } \\
\text { reported data }\end{array}$ & Y/NA & MA & & $\begin{array}{l}\text { Authors meta-analyze results obtained in more than } \\
\text { one reported experiment }\end{array}$ \\
\hline $\begin{array}{l}\text { 4-Confidence } \\
\text { intervals } \\
\text { interpretation }\end{array}$ & $\mathrm{Y}$ & CI_Interpr & & $\begin{array}{l}\text { Authors explicitly refer to CIs in the comments and/or } \\
\text { discussion of the results, e.g. confidence intervals } \\
\text { remained narrow enough...; }\end{array}$ \\
\hline $\begin{array}{l}\text { 5-Standaridzed or } \\
\text { unstandardized } \\
\text { effect size } \\
\text { interpretation }\end{array}$ & $\mathrm{Y}$ & ES_Interpr & & $\begin{array}{l}\text { Authors explicitly refer to ESs in the comments and/or } \\
\text { discussion of the results, e.g. The effect size for the } \\
\text { difference (11.94 percentage points) was large; effect } \\
\text { sizes were moderate for comparisons with the low- } \\
\text { intensity shock conditions. }\end{array}$ \\
\hline \multicolumn{5}{|l|}{$\begin{array}{l}\text { Research } \\
\text { practice } \\
\text { disclosures }\end{array}$} \\
\hline $\begin{array}{l}\text { 6-Sample size } \\
\text { determination }\end{array}$ & $\mathrm{Y}$ & Sample_size & & $\begin{array}{l}\text { Authors explicitly clarify how they determined the } \\
\text { sample size(s), e.g. power estimate, previous studies, } \\
\text { etc. Specify }\end{array}$ \\
\hline $\begin{array}{l}\text { 7-Sample size } \\
\text { stopping rule }\end{array}$ & $\mathrm{Y}$ & Data_excl & & $\begin{array}{l}\text { Authors explicitly declare if and which stopping rule } \\
\text { where adopted or the criteria to exclude data and/or } \\
\text { manage outliers }\end{array}$ \\
\hline \multicolumn{5}{|l|}{ Open Practices } \\
\hline 8-Data availability & Y & Data & & $\begin{array}{l}\text { Authors explicitly give information on how the data } \\
\text { may be obtained, e.g. posted in a repository; author } \\
\text { email, etc. Specify. }\end{array}$ \\
\hline $\begin{array}{l}\text { 9-Materials } \\
\text { availability }\end{array}$ & $\mathrm{Y}$ & Mater & & $\begin{array}{l}\text { Authors explicitly give information on how to obtain } \\
\text { the materials, equipment and/or software used in the } \\
\text { study. Specify. }\end{array}$ \\
\hline $\begin{array}{l}\text { 10-Preregistered } \\
\text { design \& analysis } \\
\text { plan }\end{array}$ & $\mathrm{Y}$ & Prereg & & $\begin{array}{l}\text { Authors explicitly declare where the study was } \\
\text { preregistered or if it is a Registered Report. Specify. }\end{array}$ \\
\hline $\begin{array}{l}\text { 11-Code } \\
\text { availability }\end{array}$ & $\mathrm{Y}$ & Code & & $\begin{array}{l}\text { Authors provide the statistical code in the paper, } \\
\text { supplementary material, or preregistration. Specify. }\end{array}$ \\
\hline
\end{tabular}




\section{Results}

The main results will relate to the scope of the application of the different practices from 2016 to 2020 within each of the two journals and their comparison. Results will be reported in figures as in 2017 and interpreted along the same lines. For example, these may include tables and figures reporting proportions of papers in Psychological Science, and the Journal of Experimental Psychology: General, from 2016 to 2020, for each of the eleven practices. 


\section{References}

Agnoli, F., Wicherts, J. M., Veldkamp, C. L. S., Albiero, P., \& Cubelli, R. (2017). Questionable research practices among Italian research psychologists. PLOS ONE, 12(3), e0172792. https://doi.org/10.1371/journal.pone.0172792

American Psychological Association. (2020). Publication Manual of the American Psychological Association, 7th edition. American Psychological Association.

Blanca, M. J., Alarcón, R., \& Bono, R. (2018). Current Practices in Data Analysis Procedures in Psychology: What Has Changed? Frontiers in Psychology, 9. https://doi.org/10.3389/fpsyg.2018.02558

Blohowiak, B. B., Cohoon, J., de-Wit, L., Eich, E., Farach, F. J., Hasselman, F., ... Riss, C. (2020, July 4). Badges to Acknowledge Open Practices. Retrieved from osf.io/tvyxz

Calin-Jageman, R. J., \& Cumming, G. (2019). The New Statistics for Better Science: Ask How Much, How Uncertain, and What Else Is Known. The American Statistician, 73(sup1), 271280. https://doi.org/10.1080/00031305.2018.1518266

Camerer, C. F., Dreber, A., Holzmeister, F., Ho, T.-H., Huber, J., Johannesson, M., Kirchler, M., Nave, G., Nosek, B. A., Pfeiffer, T., Altmejd, A., Buttrick, N., Chan, T., Chen, Y., Forsell, E., Gampa, A., Heikensten, E., Hummer, L., Imai, T., ... Wu, H. (2018). Evaluating the replicability of social science experiments in Nature and Science between 2010 and 2015. Nature Human Behaviour, 2(9), 637-644. https://doi.org/10.1038/s41562-018-0399-z

Cumming, G. (2013). The new statistics: A how-to guide. Australian Psychologist, 48(3), 161-170. https://doi.org/10.1111/ap.12018

Cumming, G. (2014). The New Statistics: Why and How . Psychological Science, 25(1), 7-29. https://doi.org/10.1177/0956797613504966

Giofrè, D., Cumming, G., Fresc, L., Boedker, I., \& Tressoldi, P. (2017). The influence of journal submission guidelines on authors' reporting of statistics and use of open research practices. PLOS ONE, 12(4), e0175583. https://doi.org/10.1371/journal.pone.0175583 
Goldacre, B., Morton, C. E., \& DeVito, N. J. (2019). Why researchers should share their analytic code. $B M J, 16365$. https://doi.org/10.1136/bmj.16365

Goodman, S. N., Fanelli, D., \& Ioannidis, J. P. A. (2016). What does research reproducibility mean? Science Translational Medicine, 8(341), 341ps12-341ps12. https://doi.org/10.1126/scitranslmed.aaf5027

Houtkoop, B. L., Chambers, C., Macleod, M., Bishop, D. V. M., Nichols, T. E., \& Wagenmakers, E.-J. (2018). Data Sharing in Psychology: A Survey on Barriers and Preconditions. Advances in Methods and Practices in Psychological Science, 1(1), 70-85. https://doi.org/10.1177/2515245917751886

Kidwell, M. C., Lazarević, L. B., Baranski, E., Hardwicke, T. E., Piechowski, S., Falkenberg, L.-S., Kennett, C., Slowik, A., Sonnleitner, C., Hess-Holden, C., Errington, T. M., Fiedler, S., \& Nosek, B. A. (2016). Badges to acknowledge open practices: A simple, low-cost, effective method for increasing transparency. PLOS Biology, 14(5), e1002456. https://doi.org/10.1371/journal.pbio.1002456

Nosek, B. A., Alter, G., Banks, G. C., Borsboom, D., Bowman, S. D., Breckler, S. J., Buck, S., Chambers, C. D., Chin, G., Christensen, G., Contestabile, M., Dafoe, A., Eich, E., Freese, J., Glennerster, R., Goroff, D., Green, D. P., Hesse, B., Humphreys, M., ... Yarkoni, T. (2015). Promoting an open research culture. Science, 348(6242), 1422-1425. https://doi.org/10.1126/science.aab2374

Nosek, B. A., Ebersole, C. R., DeHaven, A. C., \& Mellor, D. T. (2018). The preregistration revolution. Proceedings of the National Academy of Sciences, 115(11), 2600-2606. https://doi.org/10.1073/pnas.1708274114

Open Science Collaboration. (2015). Estimating the reproducibility of psychological science. Science, 349(6251), aac4716-aac4716. https://doi.org/10.1126/science.aac4716 Open Science Foundation. (2020, April 29). Guidelines for Transparency and Openness Promotion (TOP) in Journal Policies and Practices "The TOP Guidelines". 
https://osf.io/9f6gx/wiki/Guidelines/

Szucs, D., \& Ioannidis, J. P. A. (2017). Empirical assessment of published effect sizes and power in the recent cognitive neuroscience and psychology literature. PLOS Biology, 15(3), e2000797. https://doi.org/10.1371/journal.pbio.2000797

Tressoldi, P. E., \& Giofrè, D. (2015). The pervasive avoidance of prospective statistical power: Major consequences and practical solutions. Frontiers in Psychology, 6, 726. https://doi.org/10.3389/fpsyg.2015.00726

Tressoldi, P. E., Giofrè, D., Sella, F., \& Cumming, G. (2013). High Impact = High Statistical Standards? Not Necessarily So. PLoS ONE, 8(2), e56180.

https://doi.org/10.1371/journal.pone.0056180 
Study Design Template

\begin{tabular}{|c|c|c|c|c|c|c|}
\hline Question & Hypothesis & $\begin{array}{l}\text { Sampling } \\
\text { plan }\end{array}$ & $\begin{array}{l}\text { Analysis } \\
\text { Plan }\end{array}$ & $\begin{array}{l}\text { Rationale for } \\
\text { deciding the } \\
\text { sensitivity of } \\
\text { the test for } \\
\text { confirming or } \\
\text { disconfirming } \\
\text { the hypothesis }\end{array}$ & $\begin{array}{l}\text { Interpretation } \\
\text { given } \\
\text { different } \\
\text { outcomes }\end{array}$ & $\begin{array}{l}\text { Theory that } \\
\text { could be shown } \\
\text { wrong by the } \\
\text { outcomes }\end{array}$ \\
\hline $\begin{array}{l}\text { What are the } \\
\text { longitudinal } \\
\text { trend of the } \\
\text { use of eleven } \\
\text { statistical and } \\
\text { open science } \\
\text { practices in } \\
\text { the } \\
\text { Psychological } \\
\text { Science and } \\
\text { JEP-G? }\end{array}$ & $\begin{array}{l}\text { A linear } \\
\text { trend is } \\
\text { expected } \\
\text { for almost } \\
\text { all practices }\end{array}$ & $\begin{array}{l}\text { All } \\
\text { empirical } \\
\text { papers } \\
\text { published } \\
\text { between } \\
\text { January 1st, } \\
\text { 2016, to } \\
\text { December } \\
\text { 31st, } 2020\end{array}$ & $\begin{array}{l}\text { Only } \\
\text { descriptive } \\
\text { statistics }\end{array}$ & & $\begin{array}{l}\text { The authors } \\
\text { submission } \\
\text { guidelines } \\
\text { do not } \\
\text { improve the } \\
\text { use of } \\
\text { different } \\
\text { statistical } \\
\text { and open } \\
\text { science } \\
\text { practices in } \\
\text { these } \\
\text { journals }\end{array}$ & $\begin{array}{l}\text { Same as the } \\
\text { interpretations }\end{array}$ \\
\hline
\end{tabular}

